\title{
Analisis kelayakan kearifan lokal ikan larangan sebagai sumber belajar IPA
}

\author{
Aldeva Ilhami ${ }^{a, 1^{*}}$, R. Riandi ${ }^{a, 2}$, Siti Sriyati ${ }^{a, 3}$ \\ a Pendidikan IPA, Sekolah Pascasarjana, Universitas Pendidikan Indonesia, Jalan Setiabudhi No. 229, Isola, Sukasari, Kota Bandung, Jawa \\ Barat 40154 \\ ${ }^{1}$ aldevailhami2@gmail.com *; ${ }^{*}$ rian@upi.edu; ${ }^{3}$ siti_sriyati@yahoo.com \\ * korespondensi penulis
}

\begin{tabular}{ll}
\hline Informasi artikel & \\
\hline Sejarah artikel: & \\
Diterima & 10 April 2018 \\
Revisi & 29 Juni 2018 \\
Dipublikasikan & 30 Juni 2018 \\
\hline
\end{tabular}

Kata kunci:

Pembelajaran IPA

Ikan larangan

Kearifan Lokal

Sumber belajar

\section{ABSTRAK}

Pembelajaran IPA tidak dapat dipisahkan dengan konteks lingkungan termasuk di antaranya kearifan lokal. Kawasan ikan larangan merupakan salah satu kearifan lokal yang terletak di Sumatera Barat yang berkaitan dengan pelestarian lingkungan. Tujuan penelitian ini adalah untuk mengetahui kelayakan kawasan ikan larangan sebagai sumber belajar IPA. Populasi penelitian adalah siswa dan guru di SMPN 2 Gunung Omeh, Kabupaten Lima puluh Kota. Sampel penelitian berjumlah 27 orang siswa dan 3 orang guru IPA. Teknik pemilihan sampel dilakukan secara purposive sampling yaitu siswa yang mengikuti pembelajaran IPA berbasis kearifan lokal ikan larangan. Instrumen pengumpulan data menggunakan angket. Angket terdiri dari lima aspek di antaranya kemudahan akses, keamanan, efisiensi waktu, biaya dan kesesuaian dengan materi ajar. Data dianalisis dengan menghitung jawaban angket responden kemudian dipersentasekan. Hasil penelitian menunjukkan kawasan ikan larangan memiliki persentase aspek kemudahan akses sebesar 71\%, keamanan sebesar 75\%, efisiensi waktu sebesar $50 \%$, biaya sebesar $75 \%$ dan kesesuaian dengan materi ajar sebesar $89 \%$. Simpulan penelitian bahwa kawasan ikan larangan tergolong kategori layak sebagai sumber belajar IPA. Rekomendasi penelitian ini adalah agar guru IPA dapat memanfaatkan kearifan lokal tersebut untuk pembelajaran IPA supaya lebih bermakna bagi siswa.

Key word: Science Learning Ikan larangan Local Wisdom Source Learning

\begin{abstract}
Feasibility analysis of local wisdom ikan larangan as a science learning source. Science learning cannot be separated with the environmental context including local wisdom. Ikan larangan is one of the local wisdom located in West Sumatra related to environmental conservation. The purpose of this study is to determine the feasibility of Ikan larangan area as a source of science learning. The population and sample of the study were students and teachers at SMPN 2 Gunung Omeh Kabupaten Limapuluh Kota. The sample selection used purposive sampling technique which is the students followed the science learning based on the local wisdom of the Ikan larangan which numbered 27 students and 3 science teachers. The data collection instrument used a questionnaire. The questionnaire consisted of five aspects such as ease of access, security, time efficiency, cost and conformity with teaching materials. The data were analyzed by calculating of responden's answers and then they were converted to percentage. The results showed that the Ikan larangan area has percentage of accessibility aspect $7 \mathrm{I} \%$, security $75 \%$, time efficiency $50 \%$, cost $75 \%$ and suitability with teaching materials $89 \%$. The conclusion of this researchis the ikan larangan area was suitable for science learning. The implication of this research is that the science teacher can utilize the local wisdomfor science learning to create meaningful learning for the students.
\end{abstract}

Copyright (C) 2018 Universitas Ahmad Dahlan

\section{Pendahuluan}

Belajar merupakan cara untuk mendapatkan pengetahuan, pemahaman dan penguasaan konsep melalui pengalaman (Hergenhahn \& Olson, 2008).
Menurut teori kognitif sosial bahwa pembelajaran merupakan serangkaian pengolahan informasi tentang peristiwa di lingkungan kemudian ditransformasikan menjadi representasi simbolis yang berperan sebagai tuntutan bagi tindakan. Pengetahuan dan informasi 
yang diperoleh siswa tentu melalui sumber belajar. Pemaknaan sumber belajar tidak hanya dalam batasan yang sempit tetapi dapat dimaknai secara luas (Schunk, 2012). Menurut Sudjana \& Rivai (2007) sumber belajar merupakan segala sesuatu yang dapat didayagunakan baik secara langsung maupun tidak langsung, separuh atau secara keseluruhan. Hal ini menunjukkan bahwa siswa memperoleh pengetahuan tidak hanya melalui pembelajaran di sekolah akan tetapi juga dari proses pengamatan di lingkungan.

IPA (Ilmu Pengetahuan Alam) merupakan upaya sistematis untuk menciptakan, mengorganisasikan dan membangun pengetahuan dari gejala alam sekitar (Kemendikbud, 2016). Menurut NGSS, (2013) IPA merupakan cara untuk mengeksplorasi alam sekitar. Fenomena dan fakta fakta yang berada di alam sekitar menunjukkan hubungan yang tidak dapat dipisahkan dalam pembelajaran IPA. Proses pembelajaran IPA tentu menekankan agar siswa memperoleh pengalaman langsung dari lingkungan untuk mengembangkan kompetensi ilmiah. Pembelajaran IPA pada dasarnya pembelajaran yang menggunakan sains untuk mencapai tujuan pendidikan yang mengharapkan agar siswa dapat memahami masalah yang terdapat di lingkungannya. Luaran yang diharapkan dari pembelajaran IPA agar siswa memiliki literasi sains dan literasi lingkungan. Hal ini menunjukkan bahwa konteks lingkungan tidak dapat dipisahkan dalam pembelajaran IPA.

Kearifan lokal merupakan gagasan atau ide masyarakat setempat yang bernilai arif dan bijaksana yang masih dipertahankan masyarakat secara turun temurun (Ilhami \& Riandi, 2018; Khusniati, 2014; Suparmini, Setyawati, \& Sumunar, 2013). Kearifan lokal dapat dijadikan sebagai salah satu sumber belajar IPA bagi siswa karena mengandung ilmu pengetahuan. Menurut Snively \& Corsiglia (200I) bahwa sains asli (indigeneous science) sudah berkembang dalam tatanan masyarakat sejak turun temurun. Hal ini menunjukkan masyarakat sebenarnya sudah memiliki modal pengetahuan sains meskipun mereka belum mengetahui alasan secara ilmiahnya. Kearifan lokal memiliki nilai karakter yang dapat diintegrasikan dalam pembelajaran. Sebagaimana penelitian Wijana (20I5) menunjukkan bahwa pengintegrasian pendidikan karakter yang berorientasi kearifan lokal dalam mata kuliah ilmu lingkungan dapat meningkatkan softskill mahasiswa biologi. Budaya lokal yang diintegrasikan dalam model pembelajaran disebut dengan model pembelajaran berbasis budaya lokal. Model ini cukup efektif dalam meningkatkan kemampuan dasar sains siswa SMP (Suastra \& Tika, 20II). Penggunaan konteks kearifan lokal sangat penting digunakan oleh guru IPA didalam kelas. Siswa lebih mudah untuk mengkonstruksi pengetahuannya. Guru juga ikut andil dalam pelestarian potensi lokal tersebut agar tidak punah seiring perkembangan zaman (Pieter, 2016).

Pembelajaran IPA sangat relevan dikaitkan dengan kearifan lokal tentang alam sekitar karena pada hakikatnya pembelajaran IPA terkonsentrasi pada lingkungan sekitar (Tillery, Enger, \& Ross, 20II). Pembelajaran IPA mengharapkan lulusan sekolah menengah pertama untuk memahami lingkungan sekitar atau dikenal dengan istilah literasi lingkungan. Hal ini disebabkan pembelajaran IPA berkaitan erat dengan peristiwa atau fenomena yang terdapat di lingkungan sekitar. Seyogyanya salah satu output pembelajaran IPA membentuk siswa yang memiliki karakter peduli terhadap lingkungan. Sejalan dengan kerangka pengembangan pendidikan IPA bahwa siswa diharapkan mampu menerapkan kompetensi IPA yang dipelajari di sekolah dan memanfaatkan lingkungan sebagai sumber belajar (Kemendikbud, 2016).

Penggunaan lingkungan sekitar memiliki kontribusi positif terhadap pencapaian hasil belajar siswa. Beberapa penelitian tentang pemanfaatan lingkungan dalam pembelajaran membuktikan adanya pengaruh yang sangat baik. Haqiqi (2017) dalam penelitiannya tentang penerapan pembelajaran biologi dengan memanfaatkan lahan di sekitar sekolah dapat meningkatkan hasil belajar siswa pada konsep klasifikasi makhluk hidup. Peningkatan hasil belajar siswa tidak hanya terlihat pada domain kognitif tetapi juga pada domain afektif. Respon siswa setelah mengikuti pembelajaran biologi dengan menggunakan lahan sekolah menunjukkan tanggapan yang sangat baik. Penelitian Zanzibar (20I5) menerapkan pemanfaatan area Bangka Botanical Garden (BBG) melalui kegiatan kunjungan lapangan dapat meningkatkan keterampilan berpikir kreatif dan keterampilan ilmiah siswa.

Kawasan Ikan larangan merupakan salah satu situs kearifan lokal yang terdapat di Sumatera Barat. Masyarakat setempat menetapkan sebagian kawasan perairan berupa sungai sebagai daerah terlarang untuk diambil ikan dan biota lainnya sesuai batasan dan waktu ditetapkan. Sebagian wilayah menyebut dengan istilah lubuak larangan. Secara bahasa lubuak larangan terdiri dari dua kata yaitu lubuak yang berarti sungai dan larangan yang berarti tindakan yang dilarang sesuai aturan yang telah ditetapkan. Namun istilah tersebut memiliki pemaknaan yang sama yaitu sungai sebagai habitat ikan dan biota lainnya menjadi area terlarang dalam jangka waktu tertentu sesuai aturan yang telah ditetapkan. Tak hanya itu, kawasan ini memiliki aturan yang mengikat baik secara aturan adat maupun aturan pemerintah daerah. 
Keberadaan area ikan larangan hampir dimiliki disetiap kabupaten/kota di Sumatera Barat, sebagaimana yang disajikan pada Tabel I.

Tabel I. Distribusi Penyebaran Kawasan Ikan Latangan di Provinsi Sumatera Barat

\begin{tabular}{|c|c|c|}
\hline \multicolumn{3}{|c|}{ Kriteria Kelayakan } \\
\hline No & Kabupaten/Kota & Kecamatan \\
\hline $\bar{I}$ & Kab. Limapuluh Kota & $\begin{array}{l}\text { Gunuang Omeh, } \\
\text { Payakumbuh, Guguak, } \\
\text { Suliki, Akabiluru }\end{array}$ \\
\hline 2 & Kab. Pesisir selatan & $\begin{array}{l}\text { Basa Ampek Balai Tapan, } \\
\text { Tarusan, Lengayang }\end{array}$ \\
\hline 3 & Kab. Sinjunjung & $\begin{array}{l}\text { IV Nagari, Lubuak } \\
\text { Tarok }\end{array}$ \\
\hline 4 & Kab. Agam & Baso \\
\hline 5 & Kota Padang & $\begin{array}{l}\text { Padang Utara, Koto } \\
\text { Tangah, Pauh, Lubuk } \\
\text { Begalung }\end{array}$ \\
\hline 6 & Kab. Pasaman barat & $\begin{array}{l}\text { Pasaman, Kinali, Lembah } \\
\text { Malintang }\end{array}$ \\
\hline 7 & Kab. Tanah datar & $\begin{array}{l}\text { Salimpauang, Sungai } \\
\text { Tarab, Tanjung baru }\end{array}$ \\
\hline 8 & Kab. Pasaman & Lubuk Sikaping, \\
\hline 9 & Kota Pariaman & Pariaman tengah \\
\hline IO & Kab.Padang Pariaman & $\begin{array}{l}2 \text { X II anam lingkuang, } \\
\text { Lubuk aluang, IV Koto } \\
\text { Aur Melintang }\end{array}$ \\
\hline II & Kab. Solok & Kubung \\
\hline I2 & Kota Padang panjang & Padang Panjang timur \\
\hline 13 & Kota Solok & $\begin{array}{l}\text { Lubuak Sikarah,Junjung } \\
\text { sirih }\end{array}$ \\
\hline $\mathrm{I} 4$ & Kota Payakumbuh & $\begin{array}{l}\text { Lampasi Tigo Nagari, } \\
\text { Payakumbuh Barat }\end{array}$ \\
\hline
\end{tabular}

Sumber: (Ilhami \& Riandi, 2017)

Beberapa penelitian yang pernah dilakukan telah mengungkap kearifan lokal ikan larangan yang terletak di Kabupaten Dharmasraya, Kabupaten Limapuluh Kota dan Kabupaten Pesisir Selatan. Pawarti, Purnaweni, \& Anggoro (20I2) meneliti kawasan ikan larangan yang terletak di Kabupaten Dharmasraya. Masyarakat setempat menjadikan sungai Batang Pangian sepanjang I km sebagai kawasan ikan larangan. Masyarakat setempat mengenal dengan istilah lubuk larangan Ngalau Agung. Yuliaty \& Priyatna (20I4) meneliti kawasan ikan larangan yang terletak di Kecamatan Kapur IX, Kabupaten Limapuluh Kota. Masyarakat membentuk kawasan ikan larangan sepanjang $700 \mathrm{~m}$ di sungai Kapur. Penelitian Ilhami \& Riandi (2018) tentang kawasan ikan larangan yang terletak di Pandam Gadang, kecamatan Gunung Omeh. Masyarakat setempat membagi 3 bentuk kawasan larangan yang masih dilestarikan masyarakat. Masyarakat di daerah Barung Barung Balantai, Kabupaten Pesisir Selatan juga membentuk kawasan ikan larangan di sungai Batang Tarusan (Firdaus \& Huda, 2015).
Kawasan ikan larangan memiliki beberapa model yaitu sistem larangan dalam waktu tertentu dan sistem larangan untuk selamanya. Pada umumnya daerah di Sumatera Barat memiliki kawasan ikan larangan dilarang untuk selamanya meskipun ada daerah yang hanya dilarang pada jangka waktu tertentu. Ada 3 bentuk kawasan ikan larangan di Sumatera Barat yaitu tradisional, semi-tradisional dan modern. Pengelompokan kawasan tersebut berdasarkan keberadan pawang yaitu orang pintar yang dianggap memiliki kemampuan magis. Pada masa lampau masyarakat asli Sumatera Barat (minangkabau) banyak menggunakan sistem pawang untuk mengelola kawasan ikan larangan. Pada akhir tahun 1990-an terjadi transformasi manajemen melalui sistem konservasi dari pemerintah (Susilowati, 200I).

Beberapa penelitian yang telah dilakukan terkait kawasan ikan larangan di Sumatera Barat menunjukkan adanya nilai pelestarian lingkungan (Firdaus \& Huda, 2015; Ilhami \& Riandi, 2018; Pawarti et al., 2012; Susilowati, 2000). Pemanfaatan kearifan lokal sebagai sumber belajar IPA dapat membantu siswa menghubungkan dengan konsep IPA yang telah mereka peroleh dari sekolah (Parmin, 2015). Kawasan ikan larangan ini sudah menjadi bagian dari sistem sosial budaya masyarakat minangkabau sehingga layak untuk digali lebih dalam. Hal ini menjadi latar belakang penelitian ini yang bertujuan untuk mengetahui kelayakan kawasan Ikan larangan sebagai sumber belajar IPA

\section{Metode}

Penelitian ini menggunakan metode deskriptif dan tergolong pada jenis penelitian survey. Adapun metode deskriptif bertujuan untuk memberikan gambaran secara sistematis dan faktual tanpa adanya manipulasi dari subjek yang diteliti. Penelitian deskriptif yang menggunakan pendekatan kuantitatif digambarkan dengan menggunakan jumlah, ukuran dan frekuensi (Fraenkel, Wallen, \& Hyun, 2012; Sukmadinata, 2013). Lokasi penelitian di kawasan ikan larangan yang terletak di Nagari Pandam Gadang, Kecamatan Akabiluru, Kabupaten Limapuluh Kota, Sumatera Barat.

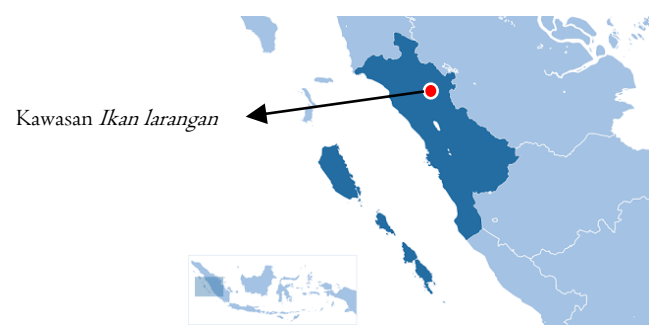


Gambar I. Kawasan Ikan Larangan Nagari Pandam Gadang, Kecamatan Akabiluru, Kabupaten Limapuluh Kota

Populasi penelitian adalah siswa dan guru IPA SMPN 2 Gunung dan sampel yang digunakan berjumlah 27 siswa dan 3 guru IPA. Pemilihan sampel dilakukan secara purposive sampling. Instrumen pengumpulan data yang digunakan adalah angket. Penggunaan angket bertujuan untuk mengetahui kelayakan kawasan ikan larangan sebagai sumber belajar IPA. Pengisian angket dilakukan oleh siswa dan guru IPA. Adapun pedoman kriteria kelayakan terdiri atas kemudahan akses, keamanan, efisiensi waktu, biaya dan kesesuaian dengan materi ajar (Najmulmunir, 2010). Skala pengukuran yang digunakan adalah skala Guttman yang berisi daftar pernyataan dalam bentuk daftar check list dengan pilihan ya / tidak. Penggunaan skala Guttman memberikan jawaban yang bersifat jelas (tegas) dan konsisten dari responden (Riduwan, 20II). Pada Tabel 2 menyajikan indikator kriteria kelayakan kawasan ikan larangan sebagai sumber belajar IPA.

Tabel 2. Kriteria Kelayakan Kawasan Ikan Larangan Sebagai Sumber Belajar IPA

\begin{tabular}{|c|c|c|}
\hline \multicolumn{3}{|c|}{ Kriteria Kelayakan } \\
\hline $\begin{array}{l}\text { Indikator } \\
\text { Kelayakan }\end{array}$ & No & Pernyataan \\
\hline \multirow[t]{5}{*}{$\begin{array}{c}\text { Kemudaha } \\
\text { n Akses }\end{array}$} & $\mathrm{I}$ & $\begin{array}{l}\text { Kawasan Ikan larangan dekat dari } \\
\text { sekolah }\end{array}$ \\
\hline & 2 & $\begin{array}{l}\text { Kawasan Ikan larangan dekat dari } \\
\text { tempat tinggal siswa }\end{array}$ \\
\hline & 3 & $\begin{array}{l}\text { Kawasan Ikan larangan yang dekat } \\
\text { sehingga dapat ditempuh dengan } \\
\text { berjalan kaki }\end{array}$ \\
\hline & 4 & $\begin{array}{l}\text { Kawasan Ikan larangan mudah } \\
\text { ditemukan }\end{array}$ \\
\hline & 5 & $\begin{array}{l}\text { Jalan menuju kawasan Ikan } \\
\text { larangan bagus sehingga tidak } \\
\text { membahayakan siswa menuju ke } \\
\text { kawasan tersebut }\end{array}$ \\
\hline \multirow[t]{3}{*}{ Keamanan } & I & $\begin{array}{l}\text { Kawasan Ikan larangan dekat } \\
\text { dengan rumah penduduk }\end{array}$ \\
\hline & 2 & $\begin{array}{l}\text { Kawasan Ikan larangan tidak dihuni } \\
\text { binatang buas yang membahayakan } \\
\text { keselamatan siswa }\end{array}$ \\
\hline & 3 & $\begin{array}{l}\text { Kawasan Ikan larangan memiliki } \\
\text { petugas atau orang yang selalu } \\
\text { menjaga di sekitar kawasan tersebut }\end{array}$ \\
\hline \multirow[t]{2}{*}{$\begin{array}{l}\text { Efisiensi } \\
\text { Waktu }\end{array}$} & I & $\begin{array}{l}\text { Perjalanan dari sekolah menuju } \\
\text { kawasan Ikan larangan kurang dari } \\
20 \text { menit dengan jalan kaki }\end{array}$ \\
\hline & 2 & $\begin{array}{l}\text { Perjalanan dari sekolah menuju } \\
\text { kawasan Ikan larangan kurang dari } \\
5 \text { menit dengan sepeda motor }\end{array}$ \\
\hline Biaya & I & $\begin{array}{l}\text { Kawasan Ikan larangan tidak } \\
\text { memungut biaya registrasi/tiket } \\
\text { masuk }\end{array}$ \\
\hline
\end{tabular}

$$
\begin{aligned}
& \text { Kesesuaian I Kawasan Ikan latangan berkaitan } \\
& \text { dengan dengan materi interaksi makhluk } \\
& \text { materi ajar hidup dengan lingkungan } \\
& 2 \text { Kawasan Ikan larangan berkaitan } \\
& \text { dengan materi pencemaran air } \\
& 3 \text { Kawasan Ikan larangan berkaitan } \\
& \text { dengan materi pelestarian makhluk } \\
& \text { hidup }
\end{aligned}
$$

\begin{tabular}{|c|c|}
\hline Persentase & Interpretasi \\
\hline $8 \mathrm{I} \% \leq \mathrm{skor} \leq \mathrm{I} 00 \%$ & Sangat Layak \\
\hline $6 \mathrm{I} \% \leq$ skor $\leq 80 \%$ & Layak \\
\hline $4 \mathrm{I} \% \leq$ skor $\leq 60 \%$ & Cukup Layak \\
\hline $2 \mathrm{I} \% \leq$ skor $\leq 40 \%$ & Kurang Layak \\
\hline $0 \% \leq$ skor $\leq 20 \%$ & Tidak Layak \\
\hline
\end{tabular}

Skor angket yang diperoleh dari guru dan siswa dijumlahkan sesuai indikator kelayakan. Rata rata skor dihitung menggunakan software Microsoft excell 2010 dalam bentuk persentase. Kategori kelayakan dengan menggunakan rubrik disajikan pada Tabel 3

Tabel 3. Rubrik Kategori Kelayakan Kawasan Ikan

(Riduwan \& Sunarto, 2013)

\section{Hasil dan pembahasan}

Kawasan ikan larangan yang terletak di Nagari Pandam Gadang, Kabupaten Limapuluh Kota adalah salah satu aset budaya masyarakat setempat. Kawasan ini sering disebut dengan istilah daerah ikan banyak karena terletak di jorong atau dusun yang bernama ikan banyak. Berdasarkan pengamatan bahwa kawasan tersebut merupakan sungai yang mengalir di sepanjang Nagari Pandam Gadang. Kawasan tersebut dikelola oleh masyarakat setempat dan telah diatur melalui peraturan adat dan pemerintah daerah. Terdapat 3 pembagian area di kawasan ikan larangan yaitu bagian hulu yang dikelola oleh pihak masjid, bagian tengah oleh pemerintahan desa dan bagian hilir yang dikelola oleh organisasi pemuda. Pada bagian tengah menjadi objek wisata unggulan yang sering dikunjungi oleh para wisatawan karena daya tarik ikan yang bergerak bebas di kawasan tersebut. Kawasan ikan larangan disajikan pada Gambar 2

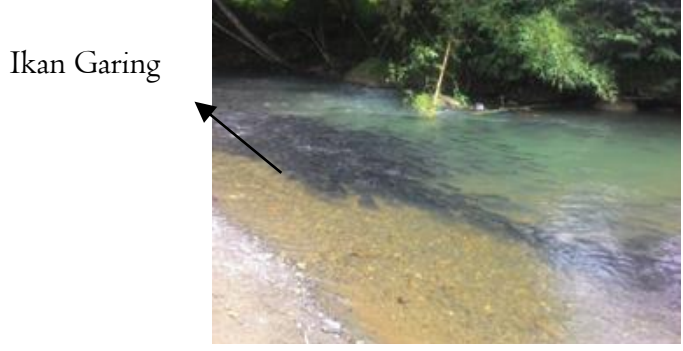

Gambar 2. Kawasan Ikan Larangan yang Terletak di Nagari Pandam Gadang 
Berdasarkan pengisian angket kelayakan kawasan ikan larangan oleh guru dan siswa disajikan pada Tabel 4.

Tabel 4. Hasil Kelayakan Kawasan Ikan Larangan Sebagai Sumber Belajar IPA

\begin{tabular}{llcc}
\hline No & \multicolumn{1}{c}{ Aspek } & Persentase & $\begin{array}{c}\text { Kategori } \\
\text { Kelayakan }\end{array}$ \\
\hline I & $\begin{array}{l}\text { Kemudahan } \\
\text { Akses }\end{array}$ & $71 \%$ & Layak \\
2 & Keamanan & $75 \%$ & Layak \\
3 & Efisiensi & $50 \%$ & Cukup Layak \\
& Waktu & & \\
4 & Biaya & $75 \%$ & Layak \\
5 & Kesesuaian & $89 \%$ & Sangat layak \\
& dengan & & \\
& Materi Ajar & & \\
\hline
\end{tabular}

Berdasarkan hasil tanggapan siswa dan guru melalui angket kelayakan menunjukkan indikator kesesuaian dengan materi termasuk kategori layak yaitu persentase skor sebesar 71\%. Indikator keamanan dan biaya juga termasuk kategori layak dengan persentase skor yang sama yaitu sebesar $75 \%$. Indikator kemudahan akses terkategori layak dengan skor sebesar 7I\%. Indikator efisiensi waktu memiliki persentase skor $50 \%$ dengan kategori cukup layak. Maka dapat disimpulkan secara keseluruhan kawasan ikan larangan termasuk kategori layak dengan persentase skor rata rata sebesar $72 \%$. Kelayakan kawasan Ikan larangan sebagai sumber belajar IPA dapat dijelaskan setiap indikatornya.

\section{Kemudahan akses}

Akses untuk menuju kawasan ikan larangan dari sekolah sudah baik karena kondisi jalan yang sudah beraspal. Kawasan tersebut sangat mudah ditemukan yaitu hanya beberapa meter dari bahu jalan utama. Hal ini sesuai dengan tanggapan siswa dan guru bahwa indikator kemudahan akses terkategori layak. Gambar 3 menunjukkan jalan menuju kawasan ikan larangan Pandam Gadang.

\section{Keamanan}

Hasil tanggapan siswa dan guru terkait indikator keamanan menunjukkan terkategori layak. Hal ini didukung dengan kawasan ikan larangan yang merupakan salah satu objek wisata di daerah setempat. Kawasan ini juga berada di sekitar pemukiman penduduk. Tidak pernah dijumpai hewan buas yang akan mengganggu keselamatan siswa. Kawasan Ikan larangan tidak memiliki petugas khusus karena memang kawasan ini belum terkelola secara maksimal oleh pemerintah daerah setempat. Meskipun demikian, berdasarkan pengamatan terlihat ada pedagang yang berada di sekitar bantaran sungai sebagaimana yang terlihat pada Gambar 3. Pedagang tersebut selalu ada setiap hari di sekitar kawasan tersebut. Siswa yang akan berkunjung tidak perlu dikhawatirkan keamanannnya. Secara keseluruhan dapat disimpulkan bahwa kawasan ikan larangan terkategori aman bagi siswa.

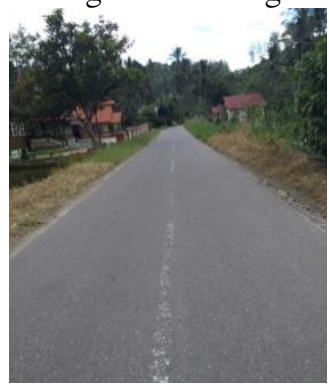

a

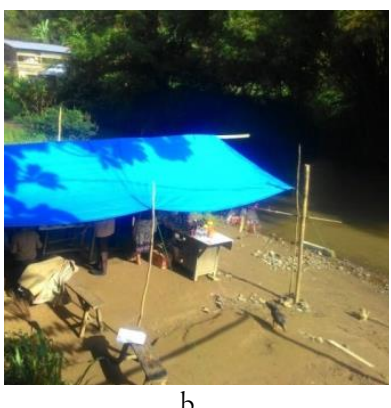

Gambar 3. Kawasan Ikan Larangan yang Terletak di Desa Pandam Gadang

\section{Efisiensi waktu}

Waktu tempuh dari sekolah ke kawasan Ikan larangan menggunakan sepeda motor yaitu sekitar 4 menit dengan kecepatan rata rata $40-50 \mathrm{Km} / \mathrm{jam}$. Jarak sekolah dengan kawasan Ikan larangan sekitar 2 - $3 \mathrm{Km}$ maka sebaiknya dibutuhkan alat transportasi dari sekolah menuju kawasan tersebut. Hal ini bertujuan agar efektif jika digunakan saat pembelajaran. Hasil tanggapan siswa dan guru terkait indikator efisiensi waktu yaitu sebesar 50\% yang terkategori cukup layak. Persentase efisiensi waktu lebih rendah dibandingkan dengan indikator kelayakan lainnya. Guru menggunakan kawasan ini pada jam pelajaran aktif dengan durasi 3 jam pelajaran. Proses mobilisasi siswa menggunakan mobil. Meskipun demikian, penggunaan kawasan ikan larangan bisa saja tidak dalam pembelajaran aktif akan tetapi diluar jam pelajaran.

\section{Biaya}

Kawasan ikan larangan masih dikelola oleh masyarakat lokal sehingga saat itu belum adanya aturan khusus yang mewajibkan pengunjung membayar tiket masuk. Para pengunjung termasuk siswa tidak memerlukan biaya masuk. Hal ini menjadi salah satu faktor pendorong kawasan ikan larangan cocok untuk sumber belajar IPA karena guru maupun siswa tidak mengeluarkan biaya untuk dapat masuk ke area tersebut. Hal ini sesuai dengan hasil tanggapan guru dan siswa dengan persentase sebesar $75 \%$ yang terkategori layak.

\section{Kesesuaian Materi}

Kawasan ikan larangan memiliki keterkaitan dengan materi IPA terutama tema lingkungan yaitu pada KD 3.7 dan KD 3.8. Namun materi yang sangat berhubungan erat dengan kawasan tersebut adalah pelestarian lingkungan. 
Tabel 5. Keterkaitan Materi IPA Pada Kawasan Ikan Larangan

\begin{tabular}{|c|c|}
\hline Kompetensi Dasar & Materi \\
\hline $\begin{array}{l}\text { 3.7 Menganalisis } \\
\text { interaksi antara makhluk } \\
\text { hidup dan } \\
\text { lingkungannya serta } \\
\text { dinamika populasi akibat } \\
\text { interaksi tersebut }\end{array}$ & $\begin{array}{l}\text { Interaksi Makhluk hidup dan } \\
\text { lingkungan } \\
\text { - } \quad \text { Komponen biotik dan } \\
\text { biotik } \\
\text { - } \quad \text { Pola interaksi makhluk } \\
\text { hidup } \\
\text { - Interaksi manusia } \\
\text { - terhadap lingkungan } \\
\text { - Pelestarian Ekosistem }\end{array}$ \\
\hline $\begin{array}{l}\text { 3.8 Menganalisis } \\
\text { terjadinya pencemaran } \\
\text { lingkungan dan } \\
\text { dampaknya bagi } \\
\text { ekosistem }\end{array}$ & $\begin{array}{l}\text { Pencemaran Lingkungan } \\
\text { - Pencemaran air }\end{array}$ \\
\hline
\end{tabular}

Kawasan ikan larangan tergolong jenis sumber belajar yang dimanfaatkan (learning resources by utilization). Menurut (Najmulmunir, 2010) jenis sumber belajar yang dimanfaatkan yaitu sumber belajar yang sudah ada di lingkungan dan tidak perlu didisain khusus ketika dimanfaatkan dalam pembelajaran. Pemanfaatan kearifan lokal membantu siswa memahami proses pembelajaran dengan adanya kegiatan observasi langsung pada objek pembelajaran. Selaras dengan hakikat pembelajaran yang seyogyanya menekankan keterampilan proses sehingga siswa lebih aktif untuk membangun pengetahuannya.

Penggunaan kawasan ikan larangan sebagai sumber belajar memfasilitasi siswa untuk mempelajari materi interaksi makhluk hidup dengan lingkungan. Kawasan tersebut memiliki nuansa kontekstual karena berkaitan erat dengan kehidupan sehari hari siswa. Siswa didorong untuk mengaitkan materi IPA tersebut dengan fenomena yang sudah membudaya pada masyarakat setempat. Pemanfaatan budaya dalam pembelajaran IPA juga dapat menumbuhkan kesadaran diri dalam menjaga kelestarian lingkungan. Guru diharapkan mampu memetakan potensi lokal yang ada di lingkungan sekitar untuk dapat diintegrasikan dalam pembelajaran IPA (Parmin, 20I5). Hal ini sejalan dengan pembelajaran IPA yang menekankan pengalaman langsung (Wiraguna, Sulastri, \& Wibawa, 20I4). Kondisi ini juga sesuai dengan tuntutan pembelajaran IPA SMP yaitu siswa mampu menerapkan konsep sains yang dipelajari di sekolah menjadi perilaku dalam tatanan masyarakat serta memanfaatkan lingkungan dan fenomena yang terjadi pada masyarakat sebagai sumber belajar (Kemendikbud, 2016).

Kearifan lokal dapat diintegrasikan dalam pembelajaran IPA dengan merekonstruksi sains asli yang sudah ada di masyarakat setempat. Pada kawasan ikan larangan yang terletak di Nagari Pandam gadang, masyarakat memiliki kepercayaan bahwa ada unsur magis yang terdapat pada kawasan tersebut. Mereka meyakini akan terjadi musibah bagi siapa saja yang melanggar aturan yaitu mencuri ikan dan mengonsumsinya (Ilhami \& Riandi, 2018). Siswa dapat menerjemahkan kepercayaan masyarakat tersebut dengan konsep IPA yaitu pelestarian makhluk hidup. Melalui adanya bagian sungai yang menjadi kawasan larangan sehingga bagian tersebut disebut sebagai breeding zone bagi ikan. Daerah ini merupakan area tempat bertelur dan pemijahan ikan untuk meneruskan keturunannya. Dampak positifnya tentu menghindari ikan dari kepunahan. Hal ini menguatkan konsep IPA yang telah dipelajari siswa dengan fenomena yang ada di sekitar mereka. Peranan guru sangatlah penting untuk membantu siswa dalam memperoleh konsep yang akan dipelajari. Guru sebagai fasilitator dalam pembelajaran dapat mendorong siswa untuk mengembangkan keterampilan berpikir kritis. Siswa tidak hanya mengikuti tradisi namun dapat mengambil makna secara ilmiah yang tersimpan dalam tradisi atau kebudayaan setempat.

Sejalan dengan teori Ausubell yang mengemukakan istilah advance organizer yang berarti kesadaran siswa terhadap struktur pengetahuan yang sedang dimilikinya sehingga informasi dapat dihubungkan dengan pengetahuan sebelumnya. Pembelajaran menjadi bermakna apabila siswa dapat menghubungkan fenomena baru dalam struktur pengetahuannya. Pada konteks ikan larangan, siswa sudah memperoleh pengetahuan awal melalui lingkungan sosial baik melalui keluarga maupun dari masyarakat setempat. Penggunaan kearifan lokal ini sebagai sumber belajar dapat menguatkan konsep IPA yang diperoleh setelah mengikuti pembelajaran IPA di sekolah yaitu konsep konservasi. Beberapa penelitian tentang pemanfaatan kearifan lokal dalam pembelajaran menunjukkan kontribusi yang sangat baik. Penelitian Hidayat, Surtikanti, \& Hernani, (2017) menunjukkan pembelajaran IPA yang terintegrasi dengan konteks lokal situ bagendit dapat meningkatkan literasi lingkungan siswa. Apriana, (2012) menerapkan pembelajaran biologi berbasis konteks lokal Aceh dalam dapat menumbuhkan karakter konservasi siswa. Peningkatan literasi lingkungan siswa juga muncul melalui pembelajaran biologi berbasis realitas lokal pulau Bangka (Mukhyati, 2015). Subhan (2017) juga menerapkan pembelajaran IPA menggunakan konteks kearifan lokal pertanian Cirebon dapat meningkatkan literasi lingkungan siswa SMP.

\section{Simpulan}


Kawasan ikan larangan masuk kategori layak dijadikan sebagai sumber belajar IPA karena memenuhi dari aspek kemudahan akses, keamanan, efisiensi waktu, biaya, dan kesesuaiannya dengan materi IPA.

\section{Ucapan terima kasih}

Terima kasih kepada LPDP dan segenap keluarga besar SMPN 2 Gunung Omeh

\section{Referensi}

Apriana, E. (2012). Pengintegrasian konsep biokonservasi dalam pembelajaran biologi sebagai upaya menumbuhkan literasi dan kesadaran lingkungan di kalangan siswa. Jurnal Pendidikan Serambi Ilmu, I2(I), I-6. Diambil dari www.serambimekkah.ac.id/download/juli20I2.pdf

Firdaus, M., \& Huda, M. (2015). Pengelolaan sumberdaya ikan di sungai (studi kasus : di Kabupaten Pesisir Selatan, Provinsi Sumatera Barat). Buletin Ilmiah MARINA Sosial Ekonomi Kelautan dan Perikanan, I(I), 4I-47. https://doi.org/I0.I5578/marina.vIiI.I026

Fraenkel, J. R., Wallen, N. E., \& Hyun, H. H. (20I2). How to design and evaluate research in education (8 ed.). New York: Mc. Graw-Hill.

Haqiqi, N. A. (2017). Pemanfaatan lahan sekolah sebagai sumber belajar untuk meningkatkan penguasaan konsep dan sikap siswa pada konsep klasifikasi makhluk hidup. Universitas Pendidikan Indonesia.

Hergenhahn, B. R., \& Olson, M. H. (2008). Theories of learning (7 ed.). Jakarta: Kencana.

Hidayat, A., Surtikanti, H. A., \& Hernani. (2017). The utilization of bagendit lake in learning to measure the environmental literacy junior high school students. In Proceeding International Conference on Mathematic s and Science Education (hal. I066-1070). Bandung: Universitas Pendidikan Indonesia. Diambil dari http://science.conference.upi.edu/icmsce20I7 /download

Ilhami, A., \& Riandi. (2017). Inventory of ikan larangan: local wisdom from west sumatra supporting contextual science learning in Indonesia. In Prosiding International Conference on Education and Learning (hal. I7-2I). Tokyo: Waseda University.

Ilhami, A., \& Riandi. (2018). Management of aquatic ecosystem based local society's knowledge: A case study of ikan larangan in pandam gadang, west sumatera. People: International Journal of Social Science, 4(I), 405-4I4. Diambil dari https://grdspublishing.org/index.php/people/ article/view/I248
Kemendikbud. (2016). Silabus mata pelajaran IPA. Jakarta.

Khusniati, M. (20I4). Model pembelajaran sains berbasis kearifan lokal dalam menumbuhkan karakter konservasi. Indonesian Journal of Conservation, 3(I), 67-74. Diambil dari https://journal.unnes.ac.id/nju/index.php/ijc/ article/view/309I/3I02

Mukhyati. (2015). Pegembangan bahan ajar perubahan lingkungan berbasis realitas lokal pulau bangka untuk meningkatkan literasi lingkungan siswa. Universitas Pendidikan Indonesia. Diambil dari http://repository.upi.edu/I9223/

Najmulmunir, N. (20I0). Memanfaatkan lingkungan di sekitar sekolah sebagai pusat sumber belajar. Region, 2(4), I-9.

NGSS. (2013). Understanding the scientific enterprise: The nature of science in the Next Generation Science Standards. Diambil 3I Maret 2018, dari www.nextgenscience.org

Parmin. (2015). Potensi kearifan lokal dalam pembelajaran IPA di SMP. In Prosiding Seminar Nasional Konservasi dan Pemanfaatan Sumber Daya Alam (hal. 278-282).

Pawarti, A., Purnaweni, H., \& Anggoro, D. D. (2012). Nilai pelestarian lingkungan dalam kearifan lokal lubuk larangan ngalau agung di kampuang surau kabupaten dharmasraya provinsi sumatera barat. In Prosiding Seminar Nasional Pengelolaan Sumberdaya Alam dan Lingkungan (hal. 98I03). Semarang: Universitas Diponegoro. Diambil dari http://eprints.undip.ac.id/37597/I/017Amin_Pawarti_edited.pdf

Pieter, J. (2016). Pembelajaran IPA berbasis kearifan lokal sebagai solusi pengajaran IPA di daerah pedalaman provinsi papua. In Prosiding Seminar Nasional Pendidikan UNCEN Tahun 2016 (hal. 44-54).

Riduwan. (20II). Skala pengukuran variabel variabel penelitian. Bandung: Alfabeta.

Riduwan, \& Sunarto. (2013). Pengantar statistika (6 ed.). Bandung: Alfabeta.

Schunk, D. H. (2012). Learning theories: an educational perspective (6 ed.). Boston: Pearson Education.

Snively, G., \& Corsiglia, J. (200I). Discovering indigenous science: Implications for science education. National Association of Research in Science Teaching.

Suastra, I. W., \& Tika, K. (20II). Efektivitas model pembelajaran sains berbasis budaya lokal untuk mengembangkan kompetensi dasar sains dan nilai kearifan lokal di SMP. Penelitian dan Pengembangan Pendidikan, 5(3), 258-273.

Subhan, A. (2017). Pengembangan bahan ajar berbasis nilai-nilai kearifan lokal pertanian padi di cirebon untuk meningkatkan literasi lingkungan siswa 
SMP (Thesis). Universitas Pendidikan Indonesia.

Sudjana, N., \& Rivai, A. (2007). Teknologi pengajaran. Bandung: Sinar Baru Algesindo.

Sukmadinata, N. (2013). Metode penelitian pendidikan. Bandung: PT. Remaja Rosdakarya.

Suparmini, Setyawati, S., \& Sumunar, D. R. S. (2013). Pelestarian lingkungan masyarakat baduy berbasis kearifan lokal. Jurnal Penelitian Humaniora, I8(I), 8-22. Diambil dari https://journal.uny.ac.id/index.php/humaniora /article/view/3I80

Susilowati, I. (2000). An Analysis of Co-Management Fisheries in West Sumatra Province, Indonesia : a Case Study of Ikan Larangan. In Proceeding of International Workshop on Fisheries Comanagement.

Susilowati, I. (200I). An application of fisheries comanagement approach of ikan larangan in west sumatra, Indonesia: the features and attributes. Journal of Coastal Development, 4(2), I07-I I7. Diambil dari https://ejournal.undip.ac.id/index.php/coastde $\mathrm{v} /$ article/view/5I84

Tillery, B., Enger, E. D., \& Ross, F. C. (20I I). Integrated science. New York: McGraw-Hill.

Wijana, N. (2015). Pengaruh pengintegrasian pendidikan karakter berorientasi kearifan lokal ke dalam materi ajar mata kuliah ilmu lingkungan untuk meningkatkan soft skill mahasiswa jurusan pendidikan biologi FMIPA UNDIKSHA. JPI (Jurnal Pendidikan Indonesia), 4(2), 647-657. https://doi.org/I0.23887/jpiundiksha.v4i2.606I

Wiraguna, I. M., Sulastri, M., \& Wibawa, C. I. (20I4). Pengaruh pendekatan CTL berbasis kearifan lokal terhadap hasil belajar siswa kelas $\mathrm{V}$ di SD Gugus IV kecamatan buleleng. Jurnal Mimbar PGSD Universitas Pendidikan Indonesia, 2(I). Diambil dari https://ejournal.undiksha.ac.id/index.php/JJPGSD /article/view/2435

Yuliaty, C., \& Priyatna, F. (20I4). Lubuk Larangan: Dinamika Pengetahuan Lokal Masyarakat Dalam Pengelolaan Sumber Daya Perikanan Perairan Sungai Di Kabupaten Lima Puluh Kota. Jurnal Sosek KP, ( (I), II5-I25.

Zanzibar, M. (20I5). Pemanfaatan Bangka Botanical Garden (BBG) Melalui Kegiatan Field Trip Berbasis Inkuiri Terbimbing Pada Konsep Ekosistem Terhadap Peningkatan Keterampilan Berpikit Kreatif Siswa SMP. Universitas Pendidikan Indonesia. 